\title{
Assessment of Virulence of Rice Gall Midge, Orseolia oryzae (Wood-Mason) Population at Warangal, Telangana, India
}

\author{
T. Sahithi", R. Sunitha Devi, S. Malathi, K.N. Yamini and G. Uma Devi \\ College of Agriculture, Professor Jayashankar Telangana State Agricultural University \\ (PJTSAU), Hyderabad-500 030, Telangana, India \\ *Corresponding author
}

\section{A B S T R A C T}

\section{Keywords}

Differential, Gall midge, Rice,

Virulence

Article Info

Accepted:

04 May 2018

Available Online:

10 June 2018
The Asian rice gall midge, Orseolia oryzae (Wood-Mason) (Diptera: Cecidomyiidae) is a serious pest of rice (Oryza sativa L.) in India. Seven distinct biotypes of the Asian rice gall midge have been characterized so far from different parts of India. Warangal rice gall midge population is designated as biotype $4 \mathrm{M}$. In order to find the virulence pattern of the rice gall midge population, single gall midge female virulence test was conducted at RARS, Warangal with three differentials, W1263 (Gml), RP2068-18-3-5 (gm3), Aganni $(G m 8)$ along with Purple (Susceptible check) and gene pyramided line (Gm4, Gm8 and $g m 3)$ of $\mathrm{F}_{3}$ generation of inter-cross, (MTU $1010 \times$ RMSGM3) $\times($ MTU $1010 \times$ RP 5923). $56 \%$ of the females were virulent among which $53.57 \%$ were virulent on purple, $50 \%$ on gene pyramided line (Gm4, Gm8 and $g m 3), 32.14 \%$ on W1263 (Gml), 30.35\% on RP2068-18-3-5 ( $\mathrm{gm} 3)$ and 7.14\% on Aganni $(\mathrm{Gm} 8)$. Sex ratio of off springs emerged is $1: 3$ and is favourable in all the differentials and gene pyramided line except W1263. It was found that Aganni $(G m 8)$ has recorded low virulence by gall midge biotype 4M.

\section{Introduction}

Rice (Oryza sativa L.) is one of the world's most important food crops which is a primary source of carbohydrate for more than half of the world's population. Many biotic and abiotic stresses often limit rice production. The Asian rice gall midge Orseolia oryzae (Wood-Mason) (Diptera: Cecidomyiidae) is a serious pest of rice (Oryza sativa L.) in India, causing an average annual yield loss of about US $\$ 80$ million. Seven distinct biotypes of the Asian rice gall midge have been characterized so far from different parts of India. Chemical control has limitations due to internal feeding habit of the pest and the prevailing hydrological and edaphological conditions during the wet season. Extensive cultivation of a single gene resistant rice varieties over a large area of India resulted in rapid development of virulent gall midge biotypes capable of overcoming host plant resistance. So far 11 gall midge resistance genes $(\mathrm{Gml}$, Gm2, gm3, Gm4, Gm5, Gm6, Gm7, Gm8, $\mathrm{Gm} 9, \mathrm{Gm} 10$ and $\mathrm{Gmll}$ ) and seven biotypes (GMB1 to GMB6 and GMB4M) of gall midge have been identified (Vijayalakshmi et al., 2006 and Himabindu et al., 2010). At Warangal, Ragolu and Jagtial biotypes GMB4M, GMB4 and GMB3, respectively, 
have been reported to occur. It has been reported that the resistance genes, gm3, Gm4 and $G m 8$ confer resistance against gall midge biotypes 1, 2, 3, 4 and 4M (Vijayalakshmi et al., 2006; Bentur et al., 2009; Dutta et al., 2014). Geographical distribution of these biotypes has been well mapped and is being monitored annually through the national gall midge biotype-monitoring studies under the All India Coordinated Rice Improvement Programme and reported minor change in virulence pattern of rice gall midge population against biotype GMB4M. In order to find the virulence pattern of the rice gall midge populations, progeny testing of a single gall midge female was conducted at RARS, Warangal with three differentials, W1263 (Gml), RP2068-18-3-5 (gm3), Aganni (Gm8) along with Purple (Susceptible check) and gene pyramided line ( $G m 4, G m 8$ and $g m 3)$ during Kharif, 2017.

\section{Materials and Methods}

The present study was carried out in green house at Regional Agricultural Research Station (RARS), Warangal during Kharif, 2017. A pot experiment was conducted using three differentials viz., W1263 (Gml), RP2068-18-3-5 (gm3), Aganni (Gm8) along with Purple (Susceptible check) and gene pyramided line (Gm4, Gm8 and $g m 3$ ) obtained from $\mathrm{F}_{3}$ lines to quantify the composition of gall midge population in terms of virulence pattern in Warangal (Plate 1). Seeds of the differentials were collected from Indian Institute of Rice Research (IIRR), Rajendranagar and a gene pyramided $\mathrm{F}_{3}$ line developed under a DBT project was taken from Institute of Biotechnology (IBT), Rajendranagar.

Seeds were soaked in water for $24 \mathrm{hrs}$ in plastic Petri dishes $(5.5 \mathrm{~cm}$ diameter). For each differential 600 seeds were used. After 24 hrs, water was drained from petri dishes to allow sprouting of seeds. On the third day of seed soaking, the germinated seeds were sown in plastic pots of 5 litre capacity containing puddled soil (15 cm deep) after levelling the soil in pots. In each pot, 3 differentials viz., W1263, RP 2068-18- 3-5, Aganni along with Purple variety and the gene pyramided line were planted, separately. Each differential was represented by one hill containing 5 or 6 seedlings. Each hill represented by a differential was labelled for identification and data recording. Plants were protected from natural infestation by gall midge by keeping the pots in a green house.

When the seedlings attained two leaves or two weeks old age, single female virulence test was conducted. On the day of infestation, each pot containing 3 differentials, check variety and a gene pyramided line were covered with a clear perforated plastic cover and tied using rubber band or thread. Each pot was infested with one female gall midge (presumed to be mated) collected during 7.30 PM to 9.00 PM near light source in the rice farm using an aspirator and released inside the pot through a small slit and then slit is sealed to prevent the escape of the insect. Such gall midge infested pots were covered with plastic cover for 2 days. On the third day, the plastic covers were removed and plants were sprayed periodically with water using a clean hand atomizer at 2 hours intervals for 2 days to create extra relative humidity to facilitate egg hatching and maggot establishment. The pots were then covered with plastic covers for 2 more days after watering. All the plants were grown for 3 more weeks until galls in each differential developed.

When differentials in all the pots showed galls, observations on number of gall midge damaged plants for each of the differential and pyramided line were recorded. The sex was identified by examining the pupae by observing under binocular microscope after 20 
to 27 days of infestation to quantify variations in virulence pattern. The male and female pupae were easily separated by their size and colour of the abdomen (Panda and Mohanthy, 1970). Male pupae are small and brown in colour while the female pupae are larger and pinkish in colour. Generally, if a single female infests each pot, all the emerging population $\left(\mathrm{F}_{1}\right)$ will be of one sex (Sahu et al., 2004). Reaction of offspring of a single female would help in identifying its biotype status. Reaction of all the females tested would help in quantifying the composition of gall midge population at the test location.

\section{Results and Discussion}

The variability in virulence within rice gall midge population was estimated through single female progeny test. 100 pots, each with three differentials, gene pyramided $\mathrm{F}_{3}$ line and Purple (Susceptible Check), were exposed to single gall midge females. Based on the plant damage (Plate 2.) in these differentials, virulence attributes of each test female was determined and results were presented in Table 1. The pots were observed for the gall development and emergence of insects from the gall.

The sex of the insect was also recorded based on sex of pupa present in the gall or sex of emerged adults or pupal case after adult emergence. The virulence attributes of the insect showed that, out of 100 tested females, only 56 were able to infest the plants. Out of these 56 females, 30 females showed virulence in Purple (Susceptible check), 28 females showed virulence in gene pyramided line ( $g m 3, G m 4$ and $G m 8$ ), 18 females showed virulence on W1263 (Gml), 17 females showed virulence in RP2068-18-3-5 (gm3), whereas, only four females were able to cause infestation on Aganni (Gm8). Similar studies were conducted by Anna Diana (2004) who studied the virulence attributes of Raipur rice gall midge population in differentials TN 1, Phalguna $(G m 2)$ and Kavya $(G m l)$ who reported that, out of 200 tested females, only 190 were able to infest the differentials. Out of these 190 females, 14 insects were able to cause infestation on Phalguna (Gm2) whereas only one female had virulent progeny on Kavya (Gml). Anbuselvi (2003) studied virulence attributes of Raipur gall midge population in differentials TN 1, Phalguna $(\mathrm{Gm} 2)$ and Kavya $(\mathrm{Gml})$ and revealed that, out of 165 females, 12 insects (7.22 per cent) produced virulent progeny on Phalguna (Gm2) and only one virulent progeny on Kavya.

Out of 30 insects collected from Purple, 20 insects $(66.66 \%)$ had female progeny and 10 $(33.33 \%)$ had male progeny, from gene pyramided line 19 insects $(67.85 \%)$ had female progeny and $9(32.14 \%)$ had male progeny, from W1263 11 insects $(61.11 \%)$ had female progeny and seven $(38.88 \%)$ had male progeny, from RP2068-18-3-5, 13 insects $(76.47 \%$ ) had female progeny and four $(23.52 \%)$ had male progeny and from Aganni three insects $(75.00 \%)$ had female progeny and one $(25.00 \%)$ had male progeny. The sex ratio in Aganni, RP2068-18-3-5, W1263, Purple and gene pyramided line was 1:3, $1: 3.25,1: 1.57,1: 2$ and $1: 2.11$, respectively, which corresponded to $1: 2-3$ ratio in all the differentials except W1263 (Fig. 3).

Slightly similar trend was observed by Vijay et al., (2008) who studied virulence composition of gall midge population on W1263, Phalguna and TN 1 differentials and reported that sex ratio in $F_{1}$ progeny corresponded to $1: 3$ ratio indicating homogenous nature of biotype 1. Similar studies were conducted under AICRIP coordinated trials at Warangal where a sex ratio of 1:3.25, 1:2.55, 1:2.1, 1:1.92 in Aganni, RP2068-18-3-5, W1263 and Purple, respectively was observed during 2015 (Progress report, IIRR, 2016) 
Fig.1 Pot wise percent virulence of rice gall midge in standard differentials and gene pyramided line

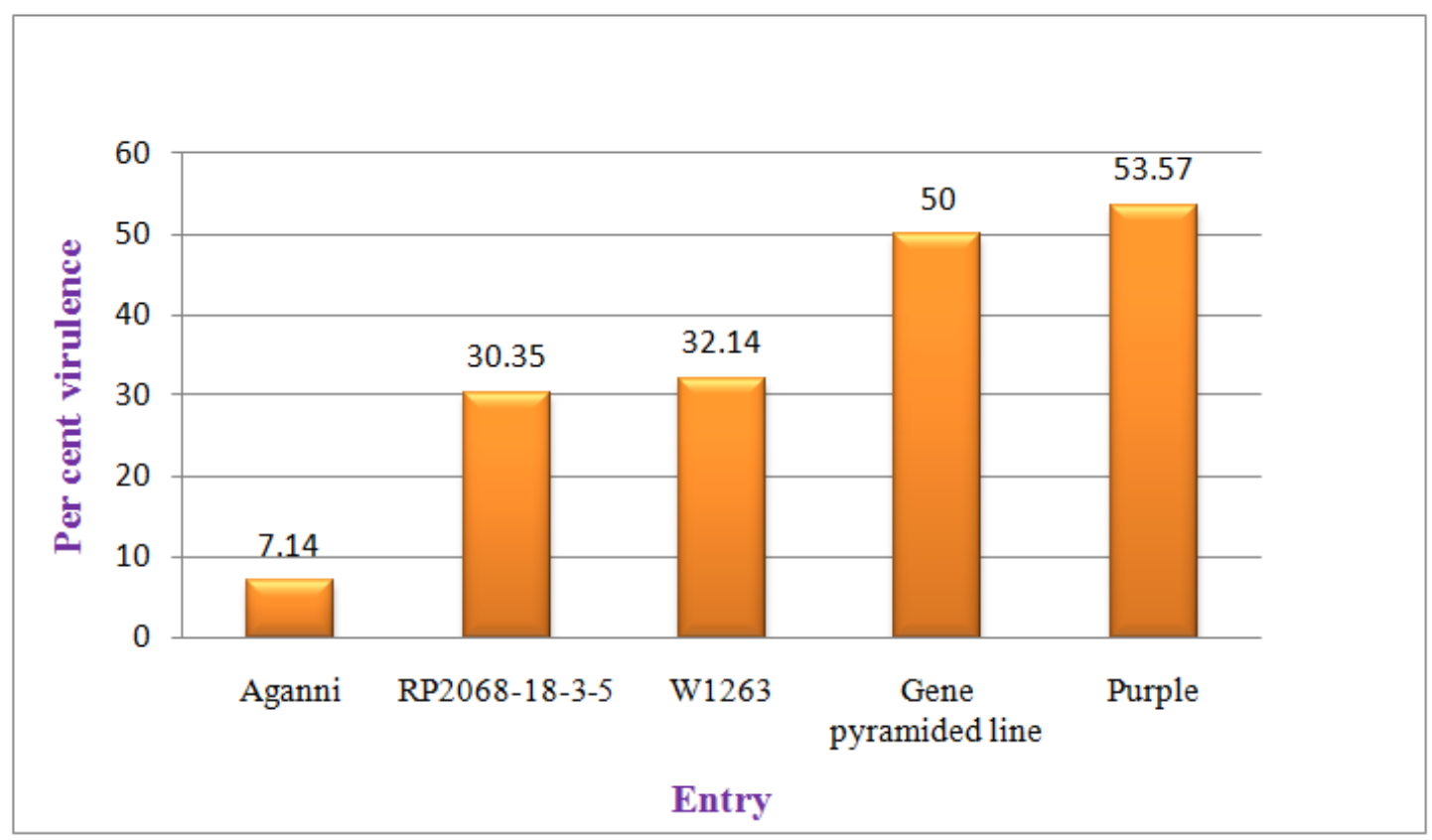

Fig.2 Plant wise per cent virulence of rice gall midge in standard differentials and gene pyramided line

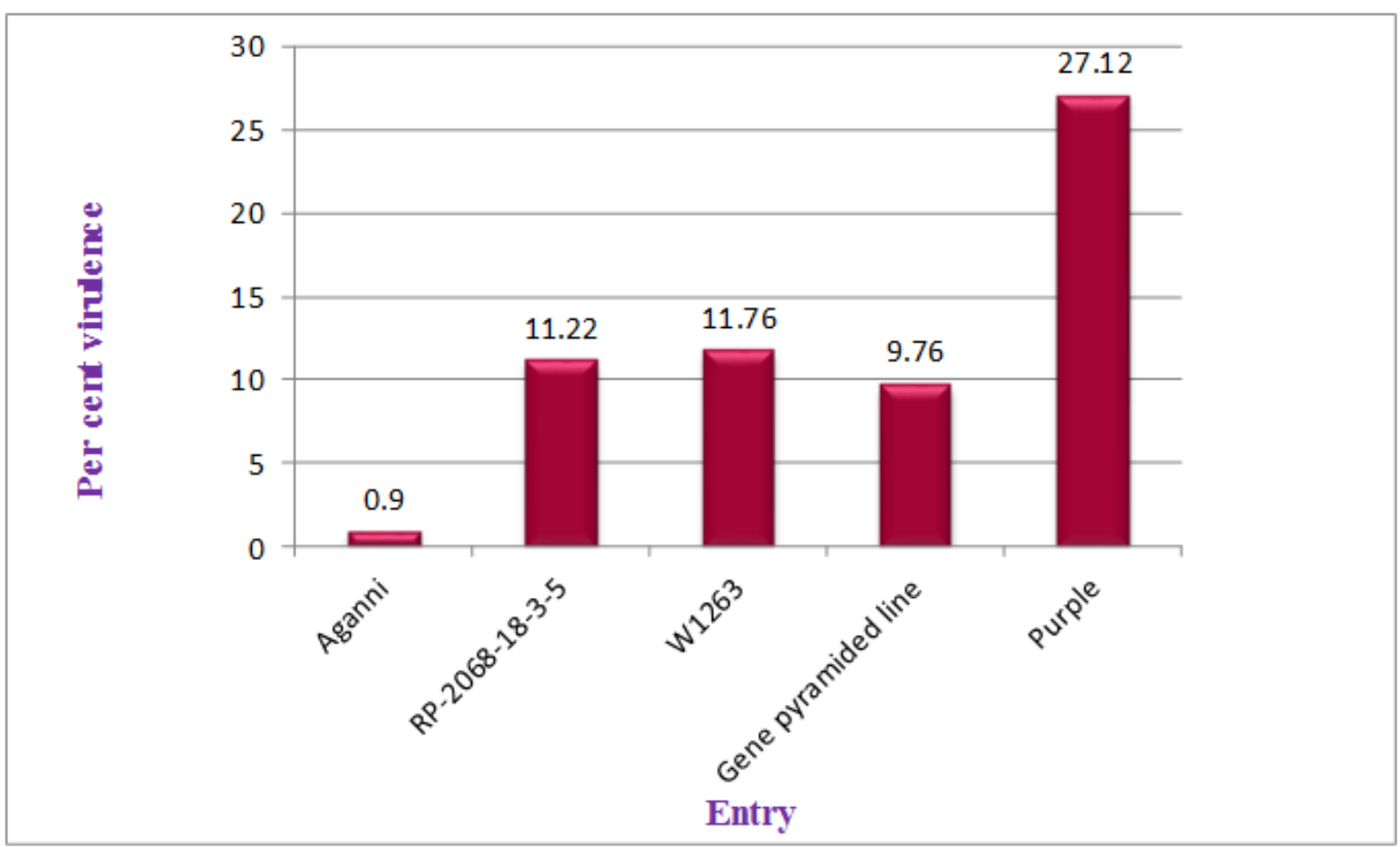


Fig.3 Sex ratio of gall midge progeny in infested rice differentials and gene pyramided line

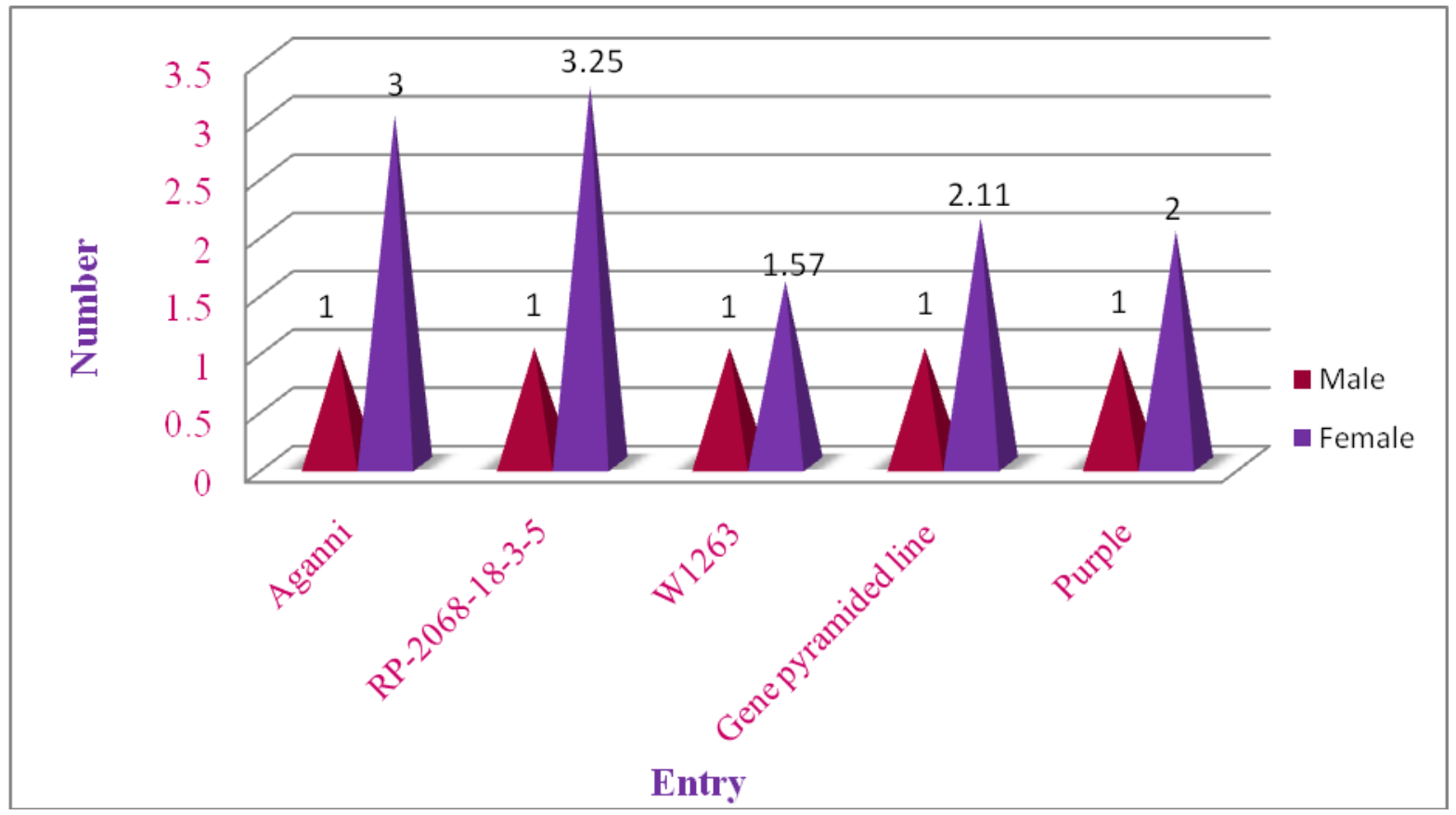

Fig.4 Molecular screening of gene pyramided $\mathrm{F}_{3}$ line for the presence of gall midge resistance genes ( $g m 3, \mathrm{Gm} 4$ and $\mathrm{Gm} 8$ )

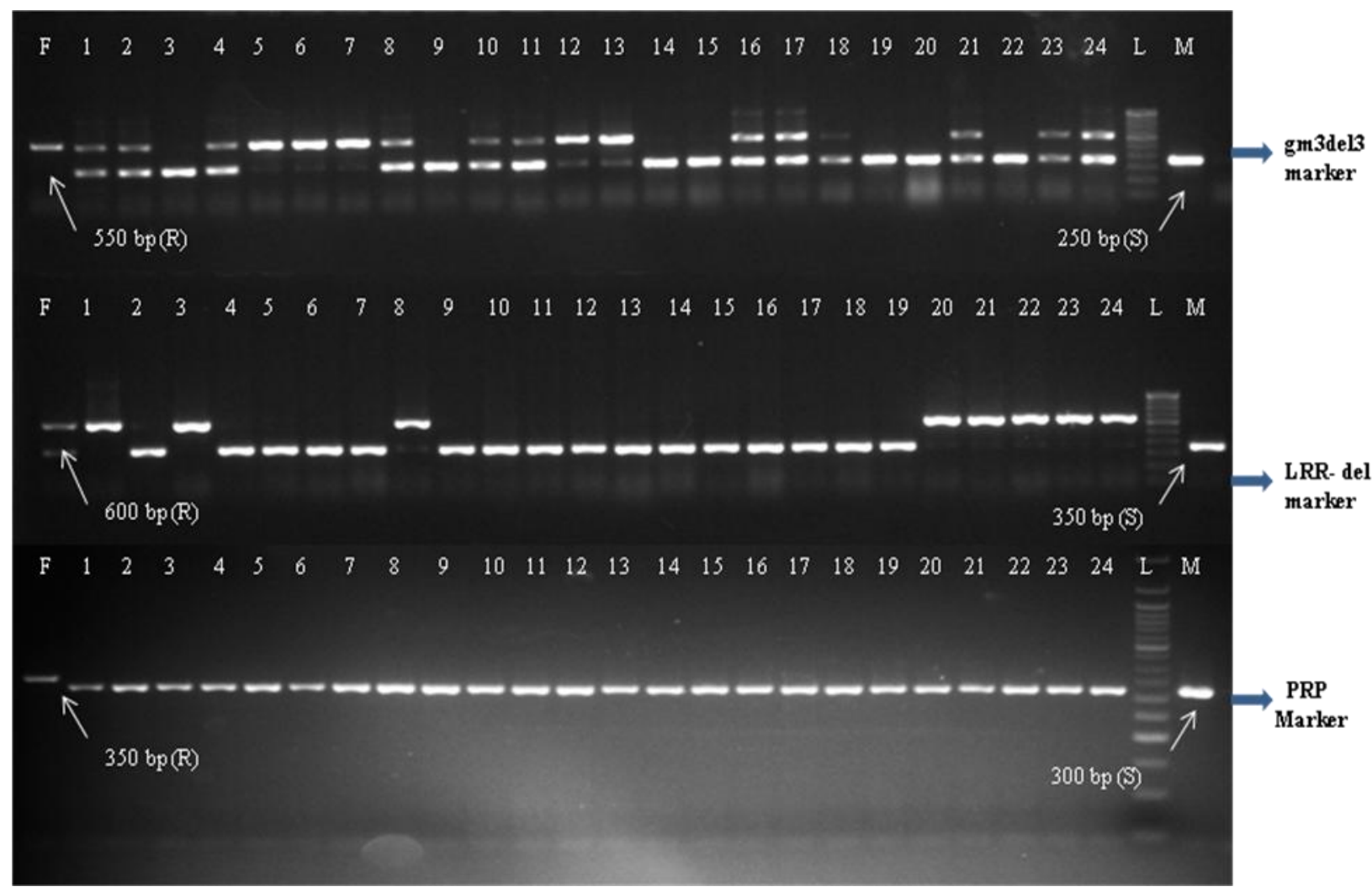


Plate.1 Gall midge virulence studies in greenhouse at RARS, Warangal

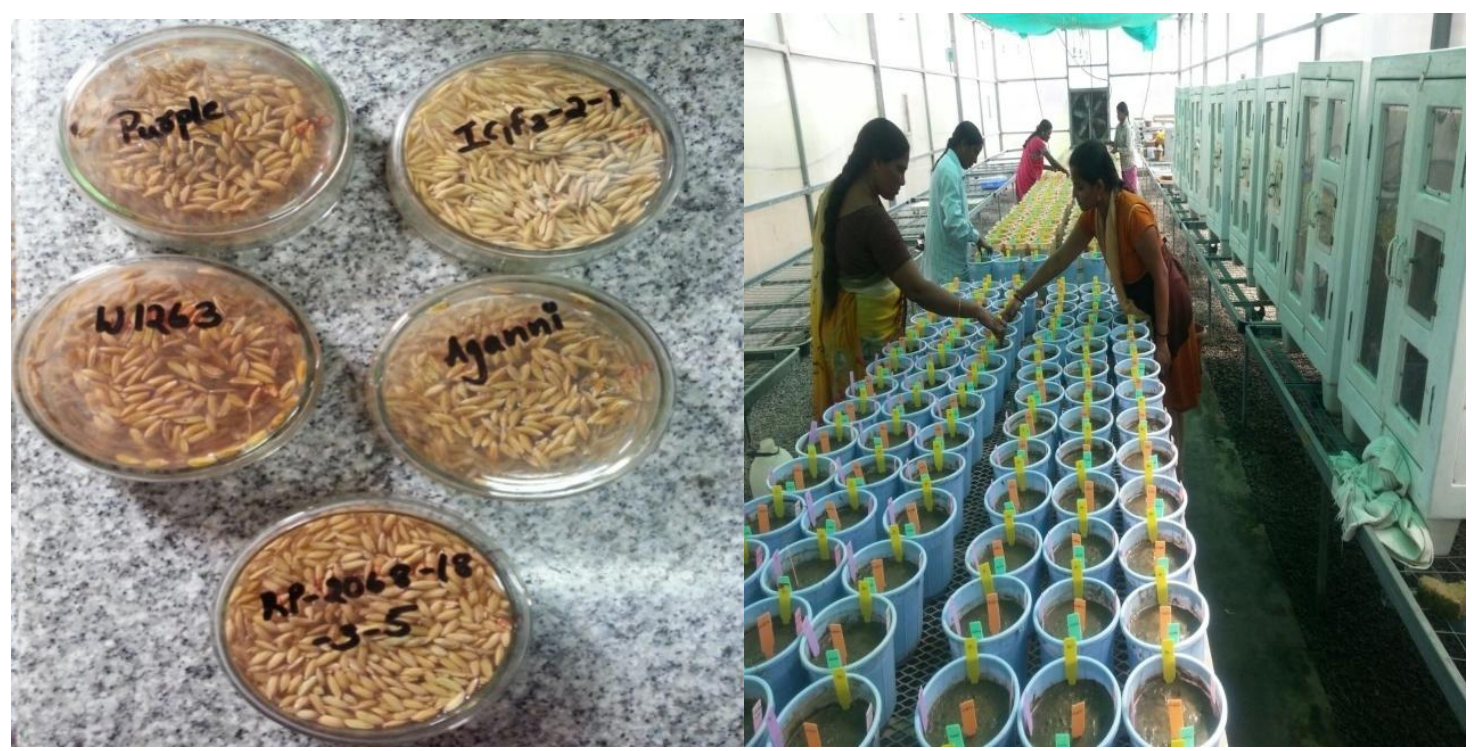

A. Soaking of seeds

B. Sowing

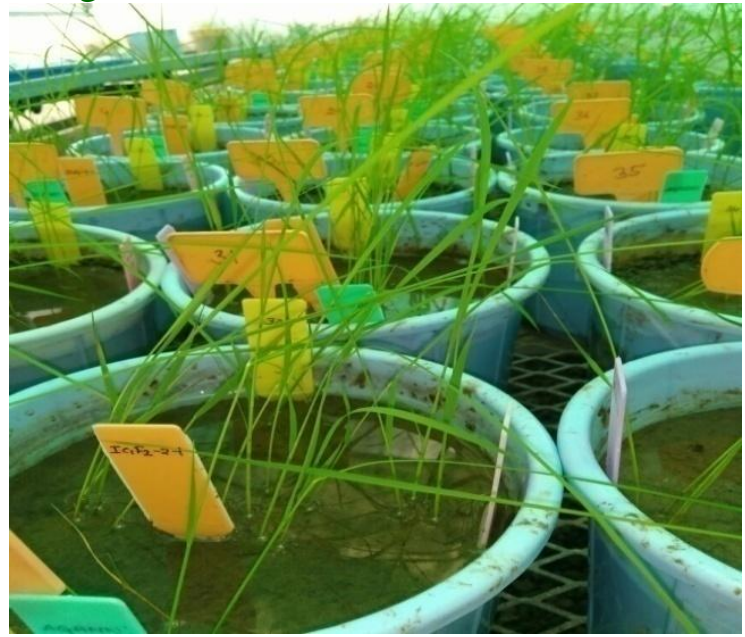

C. Rice seedlings

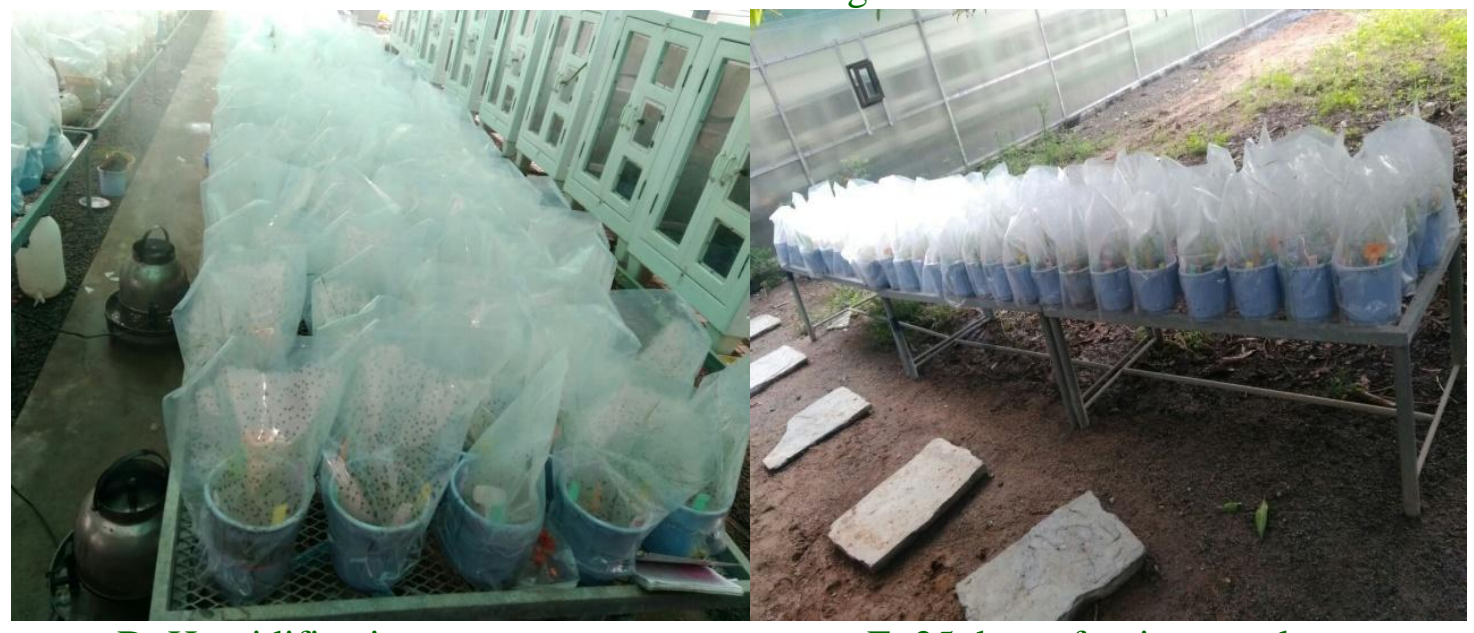

D. Humidification

E. 25 days after insect release 
Int.J.Curr.Microbiol.App.Sci (2018) 7(6): 609-618

Plate.2 Gall formation in rice differentials and gene pyramided line

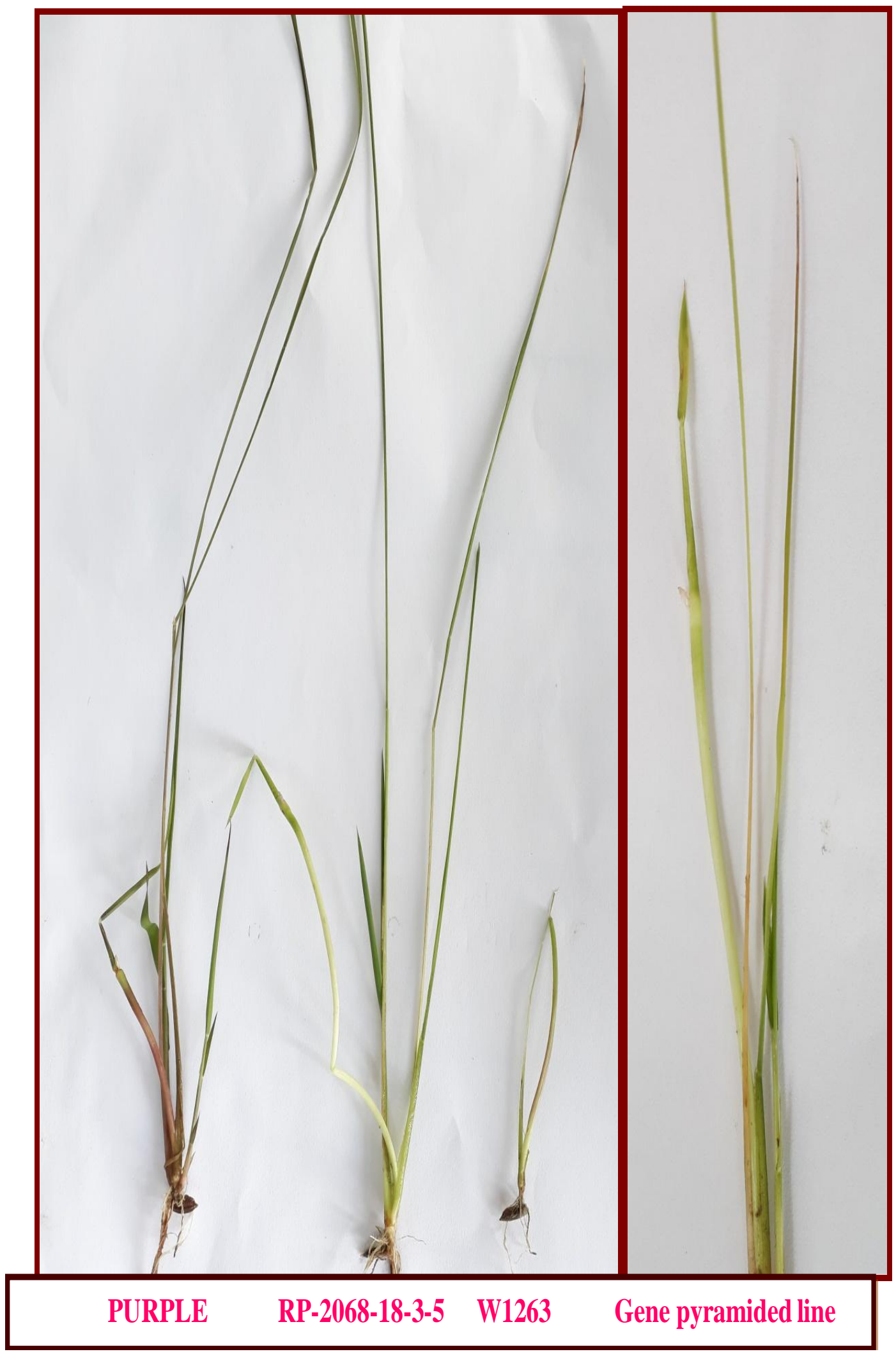


Table.1 Virulence composition of gall midge population at RARS, Warangal during Kharif, 2017

\begin{tabular}{|c|c|c|c|c|c|c|c|c|c|}
\hline \multirow[t]{3}{*}{ Differentials } & \multirow[t]{3}{*}{ R gene } & \multirow{3}{*}{$\begin{array}{l}\text { Number } \\
\text { of } \\
\text { females } \\
\text { tested }\end{array}$} & \multirow{3}{*}{$\begin{array}{l}\text { No. of pots } \\
\text { with } \\
\text { silvershoots }\end{array}$} & \multirow{3}{*}{$\begin{array}{l}\text { No. of } \\
\text { plants with } \\
\text { silvershoots }\end{array}$} & \multicolumn{2}{|c|}{$\begin{array}{c}\text { Sex of } F_{1} \text { adults } \\
\text { emerged }\end{array}$} & \multirow[t]{3}{*}{ Sex ratio } & \multicolumn{2}{|c|}{ Per cent Virulence } \\
\hline & & & & & Male & Female & & & \\
\hline & & & & & & & & Pot wise & Plant wise \\
\hline W1263 & Gml & 100 & 56 & 18 & 7 & 11 & $1: 1.57$ & 32.14 & 11.76 \\
\hline RP-2068-18-3-5 & gm3 & & & 17 & 4 & 13 & $1: 3.25$ & 30.35 & 11.22 \\
\hline Aganni & Gm8 & & & 04 & 1 & 3 & $1: 3.00$ & 7.14 & 0.90 \\
\hline $\begin{array}{l}\text { Gene } \\
\text { pyramided line }\end{array}$ & $\begin{array}{c}g m 3, \\
G m 4 \text { and } \\
G m 8\end{array}$ & & & 28 & 9 & 19 & $1: 2.11$ & 50.00 & 9.76 \\
\hline Purple & No gene & & & 30 & 10 & 20 & $1: 2.00$ & 53.57 & 27.12 \\
\hline
\end{tabular}


Results on virulence percentage of gall midge population revealed that that when considered pot wise, out of 56 females infested, $53.57 \%$ were virulent on purple, $50 \%$ on gene pyramided line (Gm4, Gm8 and $g m 3$ ), $32.14 \%$ on W1263, 30.35\% on RP2068-18-3-5 and 7.14\% on Aganni (Fig. 1). When considered plant wise, out of 56 females infested, 27.12 $\%$ were virulent on purple, $9.76 \%$ on gene pyramided line ( $\mathrm{gm} 3, \mathrm{Gm} 4$ and $\mathrm{Gm} 8$ ), $11.76 \%$ on W1263, $11.22 \%$ on RP2068-18-3-5 and $0.9 \%$ on Aganni (Fig. 2) indicating low virulence on Aganni.

Gall midge population monitoring trial during 2015 at Warangal, Sakoli and Ragolu revealed that only Aganni (Gm8) holds promise at Sakoli and Ragolu where as other differentials were found to be infested with gall midge. At Warangal, low virulence was observed on Aganni (Gm8) (Progress report, IIRR, 2016). Similar virulence was observed even during 2016 (Progress report, IIRR, 2017). In the present study also, Aganni $(G m 8)$ has low virulence against gall midge biotype 4M.

Vijay et al., (2008) studied virulence spectrum of local gall midge populations in Kodagu, Mysore and Hassan districts and revealed the presence of homogeneous population of biotype 1 where except for TN1 (susceptible), the rice gall midge populations did not infest either W1263 (Gml gene for resistance) or Phalguna (Gm2 gene for resistance) and further indicated that 100 per cent of the test individuals reacted only as biotype 1 pattern (R-R-S) in all the test locations with greater virulence against TN1 containing absence of any gene for resistance.

Warangal rice gall midge population is designated as biotype 4M. Based on earlier studies, resistance against GMB4 at Ragolu and GMB4M at Warangal is confirmed only by three genes viz., gm3, Gm4 and Gm8
(Vijaya Lakshmi et al., 2006). In the present study, the gene pyramided line taken, has all the three genes gm3, Gm4 and Gm8 and hence expected to have 'nil' gall midge damage. But the results indicated 9.76 per cent silver shoot damage in the gene pyramided line. Hence, molecular screening was conducted for this line and found that this line had showed segregation for one of the gall midge resistance genes ( $g m 3, G m 4$ and Gm8) (Fig. 4). Being a $\mathrm{F}_{3}$ generation line showing segregation for the genes could be the reason for virulence in gene pyramided line.

Virulence in differentials W1263 (Gml), RP2068-18-3-5 (gm3), Aganni (Gm8) and gene pyramided line ( $\mathrm{gm} 3, \mathrm{Gm} 4$ and $G m 8)$ indicated the necessity of continuous monitoring of virulence pattern of the local gall midge population to take necessary steps in the resistance breeding programmes or formulate other management strategies.

\section{Acknowledgement}

I sincerely thank the Director of Research, PJTSAU and Associate Director of Research, Regional Agricultural Research Station (RARS), Warangal for providing facilities to conduct the experiment at RARS, Warangal.

\section{References}

Anbuselvi, R. 2003. Virulence pattern and differentiation of Asian rice gall midge, Orseolia oryzae (Wood-Mason) population by Sequence Characterized Amplified Regions (SCARs). M. Sc. (Ag) Thesis. Indira Gandhi Agricultural University, Raipur C. G.

Anna Diana, G. 2004. Studies on Asian rice gall midge, Orseolia oryzae (WoodMason) and it's differentiation from Cynodon dactylon gall midge by RAPD analysis technique. M. Sc. (Ag) Thesis. 
Indira Gandhi Agricultural University, Raipur C. G.

Bentur, J.S., Lakshmi, V., Sama, V.S.A.K., Padmavathy, $\mathrm{Ch}$ and Himabindu, $\mathrm{K}$. 2009. Sources of resistance to the new 4M biotype of rice gall midge, Orseolia oryzae (Wood-Mason). The Indian Journal of Agricultural Sciences. 79: 844-846.

Dutta, S.S., Divya, D., Durga Rani, Ch., Dayakar Reddy, T., Visalakshmi, V., Cheralu, C., Ibohal Singh, $\mathrm{K}$ and Bentur, J.S. 2014. Characterization of gall midge resistant rice genotypes using resistance gene specific markers. Journal of Experimental Biology and Agricultural Sciences. 2 (4): 440-446.

Himabindu, K., Suneetha, K., Sama, V. S. A. K., and Bentur, J. S. 2010. A new rice gall midge resistance gene in the breeding line CR57-MR1523, mapping with flanking markers and development of NILs. Euphytica. 174 (2): 179-187.

ICAR-Indian Institute of Rice Research. 2016. Progress Report, 2015, Vol.2, Crop Protection (Entomology, Plant Pathology). All India Coordinated Rice Improvement Project, ICAR-Indian Institute of Rice Research Rajendranagar, Hyderabad.

ICAR-Indian Institute of Rice Research. 2017. Progress Report, 2016, Vol.2, Crop Protection (Entomology, Plant Pathology). All India Coordinated Rice Improvement Project, ICAR-Indian
Institute of Rice Research Rajendranagar, Hyderabad.

Panda N., Mohanty M.B. 1970. Biological studies on the paddy gall midge, Pachydiplosis oryzae (Wood-Mason) Mani in rice and its alternate hosts. Journal of Orissa University of Agriculture and Technology. 1: 8-18.

Sahu, S.C., Kar, B., Behura, R.K., Nair, S., Mohan M. 2004. Genetic conflict over sex determination in rice gall midge. pp. 17-22. In: New approaches to rice gall midge resistance in rice (Bennet, J., Bentur, J.S., Pasalu, I.C., Krishnaiah, K., Eds).- Proceedings of the International workshop, 22-24 November 1998, Hyderabad, India and International Rice Research Institute, Los Banos, Philippines.

Vijay Kumar, L., Chakravarthy, A.K., Patil, S.U and Rajanna, D. 2008. Detection of Asian rice gall midge, Orseolia oryzae (Wood-Mason) biotype1 in Kodagu District, Karnataka, South India. Journal of Entomological Research. 32(4): 265-272.

Vijaya Lakshmi, P., Amudhan, S., Himabindu, K., Cheralu, C and Bentur, J.S. 2006. A new biotype of the Asian rice gall midge, Orseolia oryzae (Diptera: Cecidomyiidae) characterized from the Warangal population in Andhra Pradesh, India. International Journal of Tropical Insect Science. 26: 207-211.

\section{How to cite this article:}

Sahithi, T., R. Sunitha Devi, S. Malathi, K.N. Yamini and Uma Devi, G. 2018. Assessment of Virulence of Rice Gall Midge, Orseolia oryzae (Wood-Mason) Population at Warangal, Telangana, India. Int.J.Curr.Microbiol.App.Sci. 7(06): 609-618. doi: https://doi.org/10.20546/ijcmas.2018.706.070 